\title{
Urodimento
}

REVISTA DE ESTUDOS EM ARTES CÊNICAS

E-ISSN 2358.6958

\section{Vício, metateatralidade e enfado em The Connection, de Jack Gelber}

\author{
Esther Marinho Santana
}

Para citar este artigo:

SANTANA, Esther Marinho. Vício, metateatralidade e enfado em The Connection, de Jack Gelber. Urdimento - Revista de Estudos em Artes Cênicas, Florianópolis, v. 2, n. 41, set. 2021.

do) DOI: http:/dx.doi.org/10.5965/1414573102412021e0204

Este artigo passou pelo Plagiarism Detection Software | iThenticate 
Vício, metateatralidade e enfado em The Connection, de Jack Gelber

Esther Marinho Santana ${ }^{1}$

\begin{abstract}
Resumo
O artigo analisa The Connection, de Jack Gelber, estreada em 1959, no Living Theatre, onde se tornou um fenômeno cultural da Off-Broadway nova-iorquina. Utilizando o recurso da peça-dentro-da-peça, a obra mescla a espera de um grupo de viciados em heroína pela chegada de seu fornecedor, apresentada de modo bastante desimpedido, com o registro do próprio processo de dramatização do cotidiano de usuários de narcóticos. Através do estudo de sua ossatura metateatral, bem como de suas ambíguas provocações a diversas tendências formais e temáticas típicas do mainstream estadunidense coetâneo, propõe-se como uma legítima singularidade o seu investimento deliberado no enfado das plateias.
\end{abstract}

Palavras-chave: Teatro estadunidense. Jack Gelber. Metateatro. Off-Broadway.

\title{
Addiction, metatheatricality, and boredom in Jack Gelber's The Connection
}

\begin{abstract}
This article analyzes Jack Gelber's The Connection, first produced in 1959, at the Living Theatre, where it became an Off-Broadway cultural phenomenon. By using the play-within-the-play device, it combines the unabashed presentation of a group of heroin addicts' anticipation for the arrival of their dealer with the dramatizing process of the narcotics users' routine. Through the study of The Connection's metatheatrical structure, and its ambiguous defiance of several formal and thematic tendencies seen in the coetaneous American mainstream arts, I argue that its greatest singularity lies in its deliberate effort to bore audiences.
\end{abstract}

Keywords: American theatre. Jack Gelber. Metatheatre. Off-Broadway.

1 Doutorado e Mestrado em Teoria e Crítica Literária pela Universidade Estadual de Campinas (UNICAMP), com estágio doutoral na City University of New York, onde foi Segal Fellow no Martin E. Segal Theatre Center. Faz parte do conselho científico e é secretária internacional para a América Latina da Edward Albee Society. esther.mrst@gmail.com

http://lattes.cnpq.br/2277445498006600 (iD) https://orcid.org/0000-0003-1370-6304 


\section{Adicción, metateatralidad y aburrimiento en The Connection, de Jack Gelber}

\section{Resumen}

Este trabajo analiza The Connection, de Jack Gelber, estrenada en 1959 en el Living Theatre, donde se convirtió en un fenómeno cultural del Off-Broadway de Nueva York. Utilizando la herramienta metateatral de la pieza-dentro-de-la-pieza, la obra mezcla la espera de un grupo de adictos a heroína por la llegada de un traficante, presentada de manera muy despejada, con el proceso de dramatización de la vida cotidiana de los usuarios de narcóticos. A partir del estudio de su estructura metateatral, así como de su ambiguo desacuerdo con las varias tendencias formales y temáticas características del arte mainstream estadunidense contemporáneo, se propone como su auténtica singularidad la producción deliberada de aburrimiento en el público.

Palabras clave: Teatro estadunidense. Jack Gelber. Metateatro. Off-Broadway. 


\section{Uma espécie de não-peça}

The Connection, a primeira peça de Jack Gelber, estreou em 15 de julho de 1959, dirigida por Judith Malina, no Living Theatre, na Off-Broadway nova-iorquina. Na cena inaugural, Jim Dunn e Jaybird falam tanto para a plateia quanto para os sujeitos no palco, apresentando-se, respectivamente, como o produtor e o escritor do espetáculo que ali acontecerá, baseado na exibição autêntica do cotidiano de um grupo de viciados em heroína. Ao longo dos dois atos, transcorridos em um único cenário, as personagens esperam pela vinda de seu fornecedor, Cowboy, enquanto andam a esmo, dormem ou contam anedotas desconexas, e, não raro, inconclusas. À dinâmica somam-se novas irrupções de Jim e Jaybird, e a participação de quatro músicos profissionais, responsáveis não pelo acompanhamento incidental dos eventos, mas pela improvisação, ao vivo, de canções de jazz.

A premissa da trama, organizada em torno da expectativa pela chegada de Cowboy, insinuava, sobretudo para o público teatral do final dos anos 1950, uma consonância com Waiting for Godot, do então já afamado Samuel Beckett, encenada pela primeira vez nos Estados Unidos em 1955², na qual Vladimir e Estragon aguardam Godot, que jamais se apresenta. Espectadores mais proficientes possivelmente se lembrariam também de Waiting for Lefty, o título de 1935 de Clifford Odets em que Lefty, a despeito de sua ausência na reunião sindical, logra, ainda assim, ser um instrumento de mobilização dos trabalhadores para uma greve geral. Em The Connection, diferentemente, Cowboy aparece ao final do primeiro ato, e, nos momentos iniciais do ato seguinte, entrega a droga prometida. Uma vez satisfeito pela heroína, o grupo de viciados, que se alternava entre perambular pelo diminuto apartamento, falar de forma fragmentária e perguntar insistentemente pelo fornecedor, sendo entrecortado, vez ou outra, pelo jazz, passa a desfalecer e a iniciar outras conversas ou monólogos desconexos, novamente em alternância com as canções, que escutam em silêncio. A presença

2 Estreada em 1953, em Paris, Waiting for Godot chegou aos Estados Unidos três anos mais tarde, dirigida por Alan Schneider em uma produção conturbada e malsucedida, em Miami. Pouco depois, Herbert Berghof dirigiu o título na Broadway, conquistando, de maneira geral, maior êxito de público e crítica. 
da tão esperada personagem resulta, conforme destaca Stephen J. Bottoms (2009, p.29), "somente em maior apatia conforme os efeitos da droga são sentidos". 3

Segundo expõe Patrice Pavis (2017), a tradição dramática clássica determina o conflito como base essencial dos diferentes gêneros teatrais, que devem apresentá-lo e encaminhá-lo em direção a algum tipo de resolução. Convencionalmente, a obra deve dar "conta da tensão das cenas e dos episódios da fábula rumo a um desenlace (catástrofe ou solução cômica)" (Pavis, 2017, p. 110), propiciando que espectador seja, durante o processo, "cativado pela ação" (Pavis, 2017, p. 110). Para a plateia de Gelber revela-se, segundo tal lógica, uma espécie de não-peça, já que a sua suposta tensão é logo sanada, e, dela, nada mais emerge para que a ação se mova. Tão logo a espera por Cowboy termina, o espetáculo continua por mais um ato, arrastando-se, carente de qualquer suspense ou de progressão dramática, em uma aparente recusa do investimento na manutenção da atenção e do interesse do público.

Os usuários de heroína, de início incumbidos de encenar a peça que Jaybird estaria criando, progressivamente se abandonam à sedação e se descuidam dos papeis, enquanto o seu próprio criador adormece, sob os efeitos da mesma substância. Até mesmo o surgimento repentino de Sister Salvation, uma religiosa que Cowboy teria trazido consigo para evitar suspeitas, não contribui para nenhum enriquecimento fabular, mostrando-se tão breve quanto estéril: ela adentra o recinto, observa-o confusa, bebe chá, tenta, sem sucesso, oferecer alguns ensinamentos cristãos, escuta um dos jovens, Solly, contando sobre o histórico de criação do uniforme do Salvation Army que ela veste, e, finalmente, parte, declarando "Eu desisto. Eu desisto"4 (Gelber, 1960, p.72)5. Após sonolências, conversas inacabadas e o uso de mais de meia hora, de sua duração total de cerca de 2h30, para apresentações de jazz, o espetáculo é selado com Jim e Jaybird desnorteados, contemplando o fracasso do que haviam idealizado encenar.

De acordo com a sua fortuna crítica imediata, The Connection foi

${ }^{3}$ simply results in further listlessness as the effects of the drug set in. (Tradução nossa)

${ }^{4}$ I give up. I give up. (Tradução nossa)

${ }^{5}$ Todas as citações em língua portuguesa do texto de Gelber aqui utilizadas são traduções nossas. 
considerada, por um lado, uma experiência teatral escandalizadora, devido à sua abordagem desinibida do uso de narcóticos, e, por outro, uma noite terrivelmente entediante, construída em torno de um enredo despido de desenvolvimento dramático e de reais conflitos. A rotulação de Louis Calta, no New York Times, exemplificava o rechaço geral à peça como nada além de "uma esculhambação vulgar” (Calta, 1959, p.30). Alguns críticos, entretanto, teceram-lhe elogios, ainda que destacando a sua morosidade. Robert Brustein (1967, p. 25) avaliava: "Porque as personagens se recusam a participar de clímaces falsos em nome da empolgação dramática, a peça não vai a lugar algum”". Jerry Tallmer utilizava os exatos mesmos termos: "No fim das contas [a peça] não vai propriamente a lugar algum" (Tallmer, 1959, p.09). E Lionel Abel defendia, ao final de uma sessão: "Se você tinha vindo para aliviar o seu tédio, você não ficará satisfeito. Você não se sentirá aliviado. Você ficará ainda mais entediado do que quando chegou”9 (Abel, 1968, p.122), indagando, repetidamente, àqueles que decidiam permanecer, "Por que você fica ali?”10 (Abel, 1968, p.122).

Ainda que apartado das demandas do grande circuito comercial, apresentado no pequeno espaço recém adaptado e inaugurado pelo Living Theatre em uma antiga loja, no Greenwich Village, era necessário que o espetáculo fosse minimamente rentável para cobrir os custos de sua montagem. Porém, mostrouse não apenas um sucesso de bilheteria em suas sessões iniciais, como seguiu no repertório da companhia pelos próximos dois anos. Ao lado de The Zoo Story, de Edward Albee, estreada poucos meses depois, em 14 de janeiro de 1960, iniciou a notória efervescência da Off-Broadway na década de 1960, quando o cenário passou a ser considerado auspicioso economicamente, por produtores e demais financiadores, e sinonímico de teatralidades inventivas e inusuais, pelas plateias.

Malgrado o parco acolhimento pela imprensa de maior circulação, The

\footnotetext{
${ }^{6}$ a farrago of dirt. (Tradução nossa)
}

Because the characters refuse to participate in false climaxes for the sake of dramatic excitement, the play goes nowhere. (Tradução nossa)

8 in the end quite properly [it] goes nowhere. (Tradução nossa)

${ }^{9}$ If you had come to be relieved of your boredom, then you will not be satisfied. You will not be relieved. You will be even more bored than you were when you first came in. (Tradução nossa)

${ }^{10}$ Why will you stay? (Tradução nossa) 
Connection venceu os Obie Awards, concedidos pela revista The Village Voice, de Melhor Peça e Melhor Produção Artística de 1960. De acordo com Kenneth Tynan em sua introdução para a primeira publicação do texto, não tardou para que se tornasse "um fenômeno cultural"11 (Gelber, 1960, p.07), graças à comoção provocada nos espectadores nova-iorquinos, divididos entre clamar às autoridades locais que um experimentalismo tão ultrajante fosse interditado (Sova, 2004, p.53), e se juntar às longas filas para as apresentações, de onde saíam tomados pela mais variada gama de reações. Conforme comentava Brooks Atkinson (1960), "os espectadores saem cambaleando pelas escadas em direção à rua em diversos estados - horror, repulsa, terror ou divertimento irônico -, achando difícil se recompor após o espetáculo”12. Afinal, o que poderia inquietar tanto no título?

\section{Heroína e metateatralidade}

Já na abertura, o espetáculo propõe a quebra da quarta parede e a ruptura da ilusão cênica. Os espectadores, ainda adentrando e se instalando no local, veem chegarem também os atores: "os intérpretes se distribuem pelo palco alguns minutos antes do início da peça”13 (Gelber, 1960, p.17), andando morosamente pelo palco, com as luzes da sala ainda acesas. Surgem, então, Jim e Jaybird, entrando pela plateia e a ela se dirigindo diretamente. Apresentam-se e anunciam o que transcorrerá: inspirado pela curiosidade de jornais, filmes, peças e livros do período pelo surto do uso de narcóticos, Jaybird teria estudado e convivido, por meses, com viciados em psicotrópicos, e os contratado para atuar em sua peça no lugar de atores profissionais.

Interessado em compreender a experiência das drogas, Jaybird alega prescindir de um texto dramático previamente escrito e fixo a ser rigorosamente seguido. Aos sujeitos teria fornecido apenas noções básicas para a caracterização

\footnotetext{
${ }^{11}$ A cultural must. (Tradução nossa)

${ }^{12}$ theatergoers have been tottering down the stairs to the street in various frames of mind - horror, revulsion, terror or ironic amusement - finding it difficult to pull themselves together after the performance. (Tradução nossa)

${ }^{13}$ the players arrange themselves on stage a few minutes before the play begins. (Tradução nossa)
} 
de cada um, nas quais o elenco se basearia livremente, seguindo de forma improvisada, tal como os músicos de jazz que ali se apresentariam, mantidos à parte de sua criação. Na produção original, os diálogos entre o autor e o produtor mencionavam os nomes de Judith Malina como a diretora do espetáculo, bem como o espaço físico do Living Theatre e o caráter modesto da companhia, aferrando pontualmente a encenação no seu contexto real. "Eu estou interessado em um teatro improvisado. Não é uma ideia nova. Só que não está sendo feito"14 (Gelber, 1960, p.18), argumenta Jaybird.

Ele promete ao público, portanto, que o que se desenrolará não é da mesma ordem do teatro encontrado em salas tradicionais, limitado por elementos textuais e materiais rígidos e pré-estabelecidos, e usualmente baseado no ensaio exaustivo dos atores para que se identificassem com seus papeis e os interpretassem a fim de produzir o efeito de realidade tipicamente naturalista. Ao contrário, Jim aponta que a experiência "não tem nenhuma base no naturalismo"15 (Gelber, 1960, p.19), e seria verdadeiramente autêntica, imprevista e única. Ainda, dada a sua ancoragem original, recusaria também as convenções formais e o tratamento temático característico do mainstream artístico estadunidense coetâneo. Em tom de zombaria, o produtor assevera: "Eu garanto para vocês que essa peça não tem uma dona de casa que vai ligar para a polícia e dizer 'Vocês poderiam correr até o [nome do teatro]. Meu esposo é um drogado"16 (Gelber, 1960, p.17). Tal imagem, diga-se de passagem, remete à esposa compadecida e comprometida em salvar seu esposo do vício em morfina, em A Hatful of Rain, de Michael V. Gazzo, êxito de bilheteria da temporada de 1955-56 na Broadway, adaptado para o cinema hollywoodiano no ano seguinte.

Na ácida revelação de que não seguirá a mesma via da obra de Gazzo, ele assume uma inclinação divergente da representação naturalista de cunho sentimental e esperançoso. No entanto, tampouco pretende adotar uma estrutura inteiramente observacional e objetiva, sob o risco de se desviar da forma criativa:

\footnotetext{
${ }^{14}$ I am interested in an improvised theatre. It isn't a new idea. It just isn't being done. (Tradução nossa)

${ }^{15}$ has no basis in naturalism. (Tradução nossa)

${ }^{16}$ I can assure you that this play does not have a housewife who will call the police and say, 'Would you please come quickly to the [name of the theatre]. My husband is a junkie. (Tradução nossa)
} 
"Para onde isso nos levaria? Um relatório sociológico sobre a hierarquia dos vagabundos da Bowery"17. Não, fora de cogitação"18 (Gelber, 1960, p. 20), destaca Jim. A peça que idealizam seria, consequentemente, a proposição de uma teatralidade outra, um uso do teatro "de uma maneira como nunca se tentou antes"19 (Gelber, 1960, p.18). Ironicamente, o produtor revela que deseja que o material também renda uma versão cinematográfica, razão pela qual trouxera consigo dois fotógrafos. Porém, garante ao hesitante Jaybird: "não vamos fazer algo à la Hollywood. Eles estão fazendo um filme avant-garde”20 (Gelber, 1960, p.24).

Para a pretensa utilização singular do teatro, debruçam-se sobre um fato ou, como Jim qualifica, um "tabu" (Gelber, 1960, p.18) - da realidade contemporânea à plateia, o uso crescente de substâncias psicoativas, não raro identificado com as vanguardas artísticas em atividade. Conforme destaca Mike Sell, a Guerra às Drogas (War on Drugs) promovida pelo governo federal dos Estados Unidos teve início efetivo com a aprovação da Décima Oitava Emenda, em 1919, que proibia o consumo e a comercialização de bebidas alcóolicas. Revogada em 1933, seu intuito de interdição de substâncias que agissem sobre o corpo e a mente migrou, nas décadas subsequentes, para diversas outras drogas ilícitas. Em 1971, a popularidade pulsante dos psicotrópicos, sobretudo da heroína, encorajou o presidente Richard Nixon a classificá-los como um inimigo nacional. A bem da verdade, o opioide já mobilizava a opinião pública há duas décadas, como se verifica na série documental intitulada The Nation's Nightmare, transmitida pela rádio CBS, de 1951-52, que o atrelava à criminalidade em grandes centros urbanos. O anúncio para o programa, publicado no New York Times, trazia o hoje célebre desenho homônimo, em preto e branco, de um jovem se injetando a droga, feito por Andy Warhol.

Nesse âmbito,

\footnotetext{
${ }^{17}$ A rua Bowery se localiza na grande região do Village nova-iorquino, e, na época, hospedava várias vertentes da contracultura em desenvolvimento nos Estados Unidos.

${ }^{18}$ Where could it lead? A sociologist's report on the pecking order of Bowery bums. No, out of the question. (Tradução nossa)

${ }^{19}$ In a way that it hasn't quite been tried before. (Tradução nossa)

${ }^{20}$ we aren't going Hollywood. They're making an avant-garde movie. (Tradução nossa)
} 
Nos anos 1950, a intersecção entre o uso criminoso de drogas com várias expressões culturais propositalmente escandalosas estava se tornando cada vez mais central na cena estadunidense. Até o final da década de 1960, o uso de drogas e a recusa do mainstream se tornariam praticamente sinônimos"21 (Sell, 2011, p.61).

Como o rápido acolhimento de The Doors of Perception, o ensaio de 1954 de Aldous Huxley sobre a mescalina, e as atividades de Timothy Leary ${ }^{22}$ com o LSD ao longo dos anos 1960 demonstram, a experimentação de psicotrópicos não apenas despertava o interesse, como terminou por ser abraçada pela contracultura estadunidense, de maneira geral. Tais substâncias eram entendidas como uma fuga do status quo comportamental burguês; um meio de expandir os mecanismos biológicos de percepção sensorial; uma contribuição para o autoconhecimento subjetivo; um veículo místico e um auxílio ao processo criativo. Ainda, o seu consumo seria um ato de resistência contra o controle opressor do Estado, exercido desde o início do século. Nessa ótica, Jaybird se situa entre as franjas da opinião pública tradicional, alvoroçada pelas denúncias da periculosidade das drogas, e da recusa de tal visão pela comunidade da contracultura e do avant-garde artístico em desenvolvimento em Nova York naquele instante, particularmente atuante no Greenwich Village.

Ainda, a alegação do dramaturgo de que colocara sujeitos realmente viciados em heroína no palco, problematiza, para Sell, a estratégia do "box-office-for-drugs plot” (Sell, 2011, p. 107), isto é, um enredo ávido pela bilheteria nascida de uma polêmica, que aludia à prática histórica do turismo para a descoberta de drogas. A título de ilustração, Sell relata o estabelecimento do bairro de Chinatown em São Francisco, na segunda metade do século XIX, que teria consolidado o consumo e a venda do ópio na cidade. Vista como uma espécie de atração exótica, a região passou a ser visitada por cidadãos brancos de classes média e alta: "passeios por bocas de ópio se tornaram uma atração imperdível entre os descolados”23 (Sell,

\footnotetext{
${ }^{21}$ In the 1950s, the intersection of criminal drug use with various kinds of purposefully scandalous cultural expression was becoming an increasingly important presence on the American scene. By the late 1960s, drug use and the refusal of the mainstream would be virtually synonymous. (Tradução nossa)

22 Leary conduziu, de 1960 a 1962, diversos estudos científicos sobre o uso do ácido lisérgico e da psilocibina na universidade de Harvard, onde também era professor. (Tradução nossa)

${ }^{23}$ tours of opium dens became a must-do among the fashionable. (Tradução nossa)
} 
2011, p.107). Ao dizer à plateia que o conteúdo apresentado não seria uma mera ficção, o dramaturgo a colocava em uma situação delicada. De espectadores teatrais de uma encenação, passariam a observadores passivos e um tanto sórdidos de uma situação real antiética, uma vez que não haveria como garantir que alguém concordara em ser observado enquanto sedado ou privado do pleno controle de suas faculdades mentais.

"O espectador pode pensar que vai ao teatro para algumas horas de distração inofensiva, mas se as personagens dramáticas são 'reais', então a sua presença é uma violação da sua privacidade, motivada por um interesse voyeurístico por shows de horrores"24 (1967, p.25), sustenta Brustein. Se ali de fato estariam não atores, mas verdadeiros viciados em uma substância entorpecedora e, quiçá, nociva, o que se poderia pensar de espectadores que compravam ingressos para vê-los fazendo uso dela? Tal como ali consta, a heroína somente induzia os sujeitos a pedir pela próxima dose e a culminar na paralisia, logo, o que se poderia dizer do público que decidia acompanhar todo o espetáculo, porventura até mesmo o apreciando?

Contudo, logo após Jaybird defender a autenticidade do que seria apresentado, Jim afirma a ficcionalidade da peça criada pelo dramaturgo, de si próprio como o produtor, e, por conseguinte, do estado dos viciados:

Esse mago das palavras aqui me inventou com o único propósito de explicar que eu e essa noite inteira no palco somos apenas uma ficção [...] O que eu quero dizer é que nós não estamos usando heroína de verdade. Vocês não acham que usaríamos a coisa pra valer, né? Afinal, narcóticos são ilegais ${ }^{25}$ (Gelber, 1960, p.19).

Segundo Brustein (1967, p.24), "Leva cerca de dez minutos para que você perceba que está vendo uma performance extraordinária, em que tudo, incluindo

${ }^{24}$ The spectator may think he attends the theatre for a few hours of harmless diversion, but if the dramatic characters are 'real', then his presence is a violation of their privacy, motivated by a voyeuristic interest in freak shows. (Tradução nossa)

25 This word magician here has invented me for the sole purpose of explaining that I and this entire evening on stage are merely a fiction [...] What I mean to say is that we are not actually using real heroin. You don't think we'd use the real stuff? After all, narcotics are illegal. (Tradução nossa) 
a sua resposta inicial, foi planejado com precisão absoluta"26. Com efeito, Jaybird e Jim inserem-se na técnica metateatral da peça-dentro-da-peça. A prometida veracidade é nada mais do que uma série de elementos arquitetados e prédeterminados por Gelber na escritura do texto, de 1957, devidamente esquadrinhados pelo Living Theatre para a montagem: dos conteúdo de todos os diálogos e monólogos, aos nomes dos sujeitos do grupo - especificamente chamados de Leach, Solly, Sam e Ernie - aos quatro músicos não nomeados²7, que, conforme ditam as rubricas, deveriam usar os seus próprios nomes (Gelber, 1960, p. 15). Até mesmo os instantes quando o jazz, "na tradição de Charlie Parker" (Gelber, 1960, p. 15), deve ser improvisado pelo quarteto, bem como as durações aproximadas para tais intervenções, são, em sua maioria, já previstos. Que se pontue, embora nutridas por improvisações e extrapolações genuínas típicas do Bebop, as faixas tocadas eram sempre as mesmas - e, na esteira do êxito da peça, acabaram lançadas pelo Freddie Redd Quartet em um álbum pela gravadora Blue Note Records, e em outro pela Felsted.

O argumento de que a plateia não tardaria a perceber que todo o espetáculo nada mais seria do que pura ficção, e, logo, regularia o seu horizonte de expectativas para compreendê-lo como uma série de manobras meticulosamente calculadas, não deve, contudo, ser pensado de forma totalizante. Conforme relembra Marvin Carlson acerca de sua experiência como espectador, no intervalo entre os atos os atores circulavam pelos corredores e pelo saguão do teatro, encantoando os presentes para pedir dinheiro para a compra de mais heroína. A interação, ausente do texto de Gelber, fora planejada pelo Living Theatre e teria sido tão bem realizada e crível que desestabilizou o próprio crítico:

Nunca, em tais circunstâncias, senti-me tão desagradavelmente desestabilizado no teatro. [...] Eu tinha aceitado a possibilidade de que aquela figura poderia de fato ser [...] um viciado de verdade, colocado para ser exibido ali... ${ }^{28}$ (Carlson, 2017, n.p.).

\footnotetext{
26 It takes about ten minutes to realize that you are witnessing an extraordinary performance, in which everything, including your initial response, has been planned with absolute precision. (Tradução nossa)

${ }^{27} \mathrm{Na}$ montagem original, o quarteto era composto por Freddie Redd, Jackie McLean, Michael Mattos e Larrie Ritchie. (Tradução nossa)

28 [...] I never in such circumstances felt so unpleasantly destabilized in the theatre [...] I had accepted the possibility that this figure might in fact be a real vagrant, perhaps even a real addict put on display...
} 
Ademais, Bottoms destaca que os membros do Freddie Redd Quartet eram notórios usuários de psicotrópicos, e, por vezes, caíam entorpecidos durante as sessões em momentos que não necessariamente coincidiam com os indicados pelo texto para que assim o fizessem (Bottoms, 2009, p.29). Igualmente, Dawn B. Sova resgata na autobiografia de Larry Rivers, amigo de diversos membros do elenco, e que viria a trabalhar com o Living Theatre, a revelação que os intérpretes ocasionalmente utilizavam heroína tanto antes das sessões quanto em cena (Sova, 2004, p.54). Aos espectadores familiarizados com a cena artística do Greenwich Village não seria nada inesperado que soubessem que os jazzistas ou os atores poderiam utilizar "the real stuff" (Gelber, 1960, p.19) conforme a colocação de Jim em sua primeira aparição, levando à confusão sobre o que seria meramente uma atuação combinada, e o que estaria escapando à performance.

Por fim, as rubricas de Gelber para o cenário indicam que, no palco, vê-se a porta para o banheiro. No segundo ato, principiado por uma apresentação de jazz, cada um dos músicos se reveza entre tocar e entrar no recinto, fechando a porta atrás de si e impedindo que a plateia veja o que lá ocorre. A seguir, Cowboy faz o mesmo, levando cada um dos viciados do grupo para dentro do espaço, onde lhes administraria a heroína. Ao confinar o opioide a um local longe do campo de visão da plateia, The Connection the confere uma aura nebulosa. Por que não mostrar o seu consumo, se o espetáculo se refere à prática de modo tão desimpedido? E, se não se pode ver a droga, como supor se é real ou não? É apenas nos instantes finais, quando Leach a injeta em si mesmo em cena, quase tendo uma overdose fatal, que a heroína é mostrada - e é, aqui, evidentemente falsa, uma vez que o episódio se repete do mesmo modo, em todas as apresentações. Até o desfecho, portanto, Gelber logra produzir expectativas vacilantes e movediças em sua plateia, que, embora decidida a apostar na ficcionalidade de todos os aspectos do espetáculo, esbarra em possíveis momentos de desorientação.

A aura de incerteza de The Connection também opera na imbricação das duas camadas diegéticas, tornadas gradativamente menos distinguíveis. Segundo 
Richard Hornby, a peça-dentro-da-peça é quase um lugar-comum do teatro renascentista, seguindo frequente até o século XVII, quando rareia, para retornar no século XX. Inicialmente, baseava-se em duas formas gerais: a ação principal era representada pela peça externa, que mantinha a peça interna destacada de si, com importância secundária; ou a ação principal se desenvolvia na peça interna, emoldurada pela peça externa. Até a modernidade, era sempre claro qual das peças, interna ou externa, era mais relevante para a fabulação dramática, assim como eram perceptíveis os contornos de cada uma, que deveriam produzir para as plateias a sensação de "estar enxergando em dobro"29 (Hornby, 1986, p.35). O teórico ressalta, ainda, que para que a estrutura seja efetivamente metateatral, ou seja, para que desafie a ilusão cênica ao explicitar a criação teatral como tal, em ambos os casos é necessário que as personagens da peça externa tenham consciência da existência da peça interna, e que a reconheçam como sendo atuada, acentuando os limites entre elas.

Já nos palcos modernos, as fronteiras entre a peça interna e a externa se tornam mais obscuras, chegando a ser dissolvidas, "desviando-nos da estrutura do metadrama, mas conservando o tom e o estilo metadramáticos"30 (Hornby, 1986, p.42). O título de Gelber é principiado com a distinção entre a peça interna, a ser conduzida pelos viciados, e a externa, aquela na qual Jaybird e Jim estão trabalhando em uma audaciosa experimentação cênica sobre o vício de heroína. Se de saída o grupo é idealizado pelo escritor como sua criação, regulado por seus termos - e cada um dos sujeitos assim se identifica -, logo passa a se rebelar e adquirir autonomia, não mais representando o conteúdo por ele ditado, e confundindo as bordas entre os dois níveis teatrais.

Ao longo do primeiro ato, Jaybird se mantém à parte dos viciados, surgindo para os instruir, mas passando a maior parte do tempo sentado ou perambulando pelo espaço dos espectadores. A plateia, assim, alterna o seu olhar entre a peça concentrada no palco, e a peça desenrolada para além dele. Em tal ponto, percebe que o escritor parece estar mais arraigado do que admite às convenções das quais

\footnotetext{
${ }^{29}$ seeing double. (Tradução nossa)

${ }^{30}$ taking us away from metadrama in structure, yet retaining the metadramatic tone and style. (Tradução nossa)
} 
prometera se livrar, uma vez que, diante dos balbucios dos sujeitos, protesta, requerendo uma técnica basilar da dramaturgia tradicional. "Vocês estão assassinando a peça. O que vocês estão fazendo? Vamos revisar outra vez. Vocês têm que fornecer todo o enredo no primeiro ato"31 (Gelber, 1960, p.33). No segundo ato, assustado pela perspectiva de sua peça desandar de todo, inquire os viciados, focados unicamente em consumir a heroína trazida por Cowboy e a oferecendo a um dos fotógrafos: "Vocês não estão exagerando? O que está acontecendo aqui? Você não está aqui para fazer esse tipo de coisa. Destrua-se a si mesmo, mas não era isso o que tínhamos combinado"32 (Gelber, 1960, p.65).

Leach, então, aponta que Jaybird, embora explorando o vício em heroína, sequer conhecia o narcótico, e deveria experimentá-lo. Ao chocado e reticente escritor, garante que estavam em uma peça, e por isso ele poderia provar a droga, pois nem ela e nem os seus efeitos seriam reais. A sugestão é, por certo, contraditória, uma vez que o argumento de Leach é o de que Jaybird deve conhecer a substância de verdade, visto que almeja a um tratamento autêntico do tema. "Você deveria saber tudo sobre isso. Quero dizer, isso é uma peça, cara. Não é de fato real"33 (Gelber, 1960, p.66), (ênfases nossas), afirma. E prossegue, deslocando o seu papel como personagem-ator para a posição de personagemespectador, trazendo o dramaturgo da peça externa para a interna: "Ei, eu quero assistir"34 (Gelber, 1960, p.66).

Jaybird cede e sai, acompanhado de Cowboy, e, quando retorna, surge pela primeira vez entrando pelo palco, onde permanece até o término do espetáculo. O olhar do público, se até aqui dividido entre os dois níveis diegéticos, passa a se focar em apenas um plano, já que a peça externa não mais enquadra a interna. Elas vão se mesclando, indistintamente, à medida que Jaybird, sedado, deixa de transitar por entre os espectadores e de se dirigir diretamente a eles, abandonando o seu exercício de criação e sendo tomado pelo opioide. Satisfeitos pela chegada

\footnotetext{
${ }^{31}$ You are murdering the play. What are you doing? Let's go over it again. You're to give away the whole plot in the first act. (Tradução nossa)

${ }^{32}$ Aren't you carrying this too far? What is happening here? You aren't here to do this sort of thing. Destroy yourself, but this wasn't in our deal. (Tradução nossa)

${ }^{33}$ You're supposed to know all about it. I mean this all is a play, man. It's not really real. (Tradução nossa)

${ }^{34}$ Hey, I want to watch. (Tradução nossa)
} 
de Cowboy, os viciados simplesmente seguem em cena, sem instruções do que deveriam fazer ou dizer, acompanhados pelos momentos de jazz.

Ainda que a posição de Jaybird, previamente apartada, seja fisicamente integrada à das suas personagens - estão todos no palco, no mesmo plano da diegese, sob os mesmos efeitos da heroína - não há qualquer entendimento entre eles. Cada qual parece enclausurado em suas sensações individuais, e a alegação do escritor de que "Existe um muro entre você e eu, Jim"35 (Gelber, 1960, p.74) se aplica a todas as relações. Não apenas o que os outros dizem não produz nenhuma significação de valor para ele, como também parece um conteúdo enfadonho para si próprio e para a plateia. Sonolento, ele observa os diálogos desarticulados ao seu redor, reclamando: "Tudo o que vocês fazem é falar, falar, falar. Essa balbuciação não tem fim? Essa parte da peça deveria ser de pura violência. Eu não peço por mim, mas pensem na plateia“36 (Gelber, 1960, p.83). Segundo aponta, ele planejara um segundo ato de tensões emocionantes, e admite até mesmo ter pensado na adoção de heróis, "a base do drama ocidental, sabe"37 (Gelber, 1960, p.84). Desacordado em meio ao jazz e às falas, enfim desperta, nos momentos derradeiros do espetáculo, resmungando, "O que aconteceu com o final? Nós perdemos o fim. Bem, bem. Tudo está bem”38 (Gelber, 1960, p.91), em uma referência ao título shakespeariano All's Well That Ends Well (em tradução livre, Tudo está bem quando acaba bem), cuja ação é concluída com o sucesso súbito de um conturbado conflito amoroso. A alusão é marcadamente irônica e autoconsciente, já que ali nenhuma tensão fora devidamente instalada, e tampouco se pode dizer que se ruma para um final feliz.

Para o público torna-se então incontestável que Jaybird, malgrado seu anúncio inicial de que elaboraria uma outra teatralidade, estivera sempre preso a fórmulas dramáticas das mais tradicionais. A heroína, longe de o inspirar a se desviar da estética dominante, termina por alinhá-lo ainda mais a convenções

\footnotetext{
35 There is this wall between you and me, Jim. (Tradução nossa)

${ }^{36}$ All you do is talk, talk, talk. Is there no end to this babbling? [...] This part was to be blood and guts drama. It's not for me that I plead with you. Think of the audience. (Tradução nossa)

${ }^{37}$ the basis of Western drama, you know. (Tradução nossa)

${ }^{38}$ What happened to the ending? We've lost the end. Well, well. All's well. (Tradução nossa)
} 
canônicas, reforçadas pela última chegada de Jim, que lhe pede que crie ao menos um final que satisfaça o público pagante. Novamente recorrendo a Shakespeare um nome tradicionalmente bem recebido pelos espectadores, sobretudo no mundo teatral anglófono, pois considerado de valor artístico inquestionável -, o produtor brinca e sugere um desfecho trágico em que todas as personagens sejam mortas. Enfim, aventa que deverão trazer mulheres sensuais para que a futura versão fílmica obtenha o sucesso não conquistado pela peça. Jaybird, contudo, rebate:

A culpa foi minha. Eu cheguei a pensar que talvez os médicos assumiriam. Essa é a minha mensagem para hoje. Talvez eu deva ser o herói. Mas eu não sou um mártir. Nós não precisamos de mulheres. Nós precisamos de um mártir. Deixe os médicos dadaístas tomarem o controle dos narcóticos ${ }^{39}$ (Gelber, 1960, p. 94).

Suas noções composicionais são um amálgama de diversas estruturas norteadoras do mainstream cultural, com uma ideia desengonçada do que seria uma resposta contrária a elas. Os médicos tomando o controle evocariam um desfecho redentor e moralista, que confia no poder institucional da medicina para resgatar viciados em narcóticos, na esteira dos produtos da Broadway ou de Hollywood. A existência de uma mensagem apreensível afirmaria a arte que se propõe a oferecer uma moral ou um ensinamento final. A apresentação de um herói se coadunaria não apenas com a tradição trágica ocidental, conforme comentara anteriormente, como também com os tipos heroicos martirizados pelo drama ou o melodrama burgueses. Já a ideia de médicos dadaístas assumindo o tráfico de narcóticos, por sua vez, parece surgida da trama de um filme de gangsters, com insólitos toques de experimentação, segundo o estereótipo que Jaybird teria do avant-garde de seu tempo.

Tal imagem não deixa de ser risível, e se pode aventar que Gelber a utiliza como uma provocação às artes contemporâneas, e, porventura, como uma espécie de autocrítica. Ou seja, a personagem do escritor é secretamente arraigada às convenções, a despeito de sua postura depreciativa e da tentativa de se

${ }^{39}$ It was my fault. I thought perhaps the doctors would take over. That's the message for tonight from me. Maybe I'm supposed to be the hero. But I'm not a martyr. We don't need women. We need a martyr. Let Dada doctors take control of the narcotics. (Tradução nossa) 
desenvencilhar delas a qualquer custo. Em seu ensaio de subversão, acaba por confiar em itens que sequer sabe bem como utilizar, como a improvisação, o antinaturalismo, o shock effecte fotógrafos vanguardistas. Porém, desfalecido pela heroína, perde o controle do seu material criativo. Ao final, Jaybird, aquele que queria reinventar a estética teatral, não chega à conclusão alguma sobre como poderia ter desenvolvido uma noção verdadeiramente original. Ao contrário, afirma a necessidade da fluidez e da harmonia de fórmulas tradicionais, e se admite escandalizado por seu próprio tema provocador. No entanto, justamente por não ter finalizado sua criação, não afundara de todo em velhas fórmulas:

Mas uma coisa eu aprendi sobre o teatro. Eu acho que tudo se encaixa. [...] Eu não aprendi nada. Eu sabia. Ache um horror. Então tente dizer às pessoas que não é um horror. E então eu tenho a audácia de ficar horrorizado. [...] Sem médicos, sem heróis, sem mártires, sem Cristos. É uma pontuação muito boa. Eu não me queimei. Talvez fiquei abaixo da média, mas não me queimei ${ }^{40}$ (Gelber, 1960, p. 95-96).

Com a peça interna desintegrada na externa, The Connection termina.

\section{"A very good score"}

Em um anúncio publicado no jornal The Village Voice, em 1959, o produtor e entusiasta da Off-Broadway H. B. Lutz respondia à rejeição inicial ao espetáculo por plateias conservadoras, defendendo não se tratar de "um dos típicos musicais da Broadway, naquele estilo adocicado de apresentações de festivais de cidadezinhas pequenas" ${ }^{41}$. Logo, argumentava, não poderia mesmo agradar àqueles ávidos por moldes já conhecidos e de fácil aceitação. Se Gelber não empregara as convenções temáticas ou formais típicas do grande circuito nova-iorquino, conseguiu, com a sua peça, conquistar o ineditismo que Jaybird almejara?

À primeira vista, o desdém ao naturalismo, as perturbações da ilusão

\footnotetext{
${ }^{40}$ But one thing l've learned about the theatre. I believe it all fits together. [...] I didn't learn anything. I knew it. Find a horror. Then you try to tell people it isn't a horror. And then I have the gall to be horrified. [...] No doctors, no heroes, no martyrs, no Christs. That's a very good score. I didn't get burned. Maybe short counted, but not burned. (Tradução nossa)

${ }^{41}$ one of the regular Broadway, county-fair-type, spun-sugar musicals. (Tradução nossa)
} 
dramática, o emprego sem precedentes dos jazzistas, e a contemplação desembaraçada do uso da heroína indicariam o êxito de The Connection em cunhar uma teatralidade ímpar, e, mais, em estar em plena consonância com as insurreições levantadas pela contracultura em ebulição no período sessentista. Por outro lado, o recurso da peça-dentro-da-peça foi bastante recorrente no teatro renascentista, e, na obra sessentista, resulta em uma quebra do efeito cênico de realidade em perfeito alinhamento ao que Hornby (1986) descreve como a arquitetura adotada por diversos outros dramaturgos ao longo do século XX.

Pautado rigorosamente em um texto escrito, o espetáculo não dá margens para que a improvisação e a autenticidade prometidas aos espectadores ocorram de maneira ostensiva. Conquanto o ambiente boêmio do Greenwich Village adicionasse eventuais fatores ambíguos e imprevistos às sessões, há que se considerar que eram elementos externos e circunstanciais, não havendo nada no material original de Gelber, para além da prescrição das apresentações musicais, que de fato gere improvisações. O Bebop era, aqui, majoritariamente uma evocação um tanto jocosa do suposto princípio composicional da obra, que confiava no jazz - baseado, quando tocado ao vivo, na experimentação improvisada para obter a sua descontinuidade, os fraseados irregulares e a complexidade melódica - para a afirmação de um caráter não planejado.

Jamais restritas ao uso corrente de um discreto acompanhamento acessório para as cenas, e tampouco subsidiárias do desenrolar da ação, como nos book musicals ${ }^{42}$, as faixas musicais se sobressaíam o suficiente para destoar do fluxo dramático, sem, porém, interrompê-lo. Nesse sentido, operavam como um meio tanto de indicação e caracterização da vizinhança onde se localiza o apartamento de Leach, o Village, também a sede do Living Theatre, quanto de autoinserção na cultura hipster"3, ou hep(cat), celebrada nos diversos bares da região. Originalmente, os criadores e intérpretes do Bebop punham convenções da técnica

\footnotetext{
${ }^{42}$ Especialmente célebres na Broadway, os book musicals são musicais onde as canções e os números de dança integram e fazem progredir os eventos da diegese.

43 O jazz tem origem entre os negros dos Estados Unidos. A tendência hipster, surgida nos anos 1940 nos músicos e apreciadores do estilo musical, já havia sido consideravelmente esvaziada de sua carga histórica inicial quando foi apropriada por artistas brancos, no final da década de 1950. No controverso ensaio de Norman Mailer, The White Negro: Superficial Reflections on the Hipster, de 1957, foi defendida como um modelo de insurreição cultural e de libertação individual, que deveria ser tomado por todos os cidadãos indispostos contra o status quo vigente.
} 
musical à prova com um objetivo de radical confrontação mercadológica, estendendo a postura de não-conformismo a diversas de suas outras manifestações culturais, sociais e políticas - dentre as quais, o conhecido uso de maconha e heroína.

Todavia, a tônica do espetáculo com relação aos narcóticos afasta-se de tal enaltecimento. Se não dedica a eles um viés moralista e condenatório, abstendose de transformar os viciados em veículos para uma conscientização melodramática sobre os malefícios das drogas, tampouco exalta o seu consumo. Suas propriedades químicas figuram desprovidas de uma caracterização que as apresente como enriquecedoras da percepção subjetiva ou sensorial, ou propiciadoras de um novo estado de criatividade. Também não há efetivo investimento no argumento de que seriam uma ferramenta de oposição sociopolítica a um Estado proibitivo ou a quaisquer outras ordens vigentes. Todos os usuários, uma vez sedados pela heroína, não apenas não se expressam e nem se comunicam eficientemente, como não realizam nada. Para eles, há meramente o autocontentamento e a estase, ambos temporários - e viciantes. E para Jaybird há, ainda, o descontrole e o malogro do exercício criativo.

The Connection também se nega a seguir a mesma via de crítica da identidade e dos padrões de comportamento normativos, ou square, particularmente abraçada pela literatura Beat - encabeçada por William Burroughs, Allen Ginsberg, Gregory Corso e Jack Kerouac, e logo desmembrada em autores diversos. Contrapostos aos hipsters, os squares eram rotulados como antiquados por serem convencionais. Se, a princípio, eram entendidos a partir da não familiaridade com as experimentações do jazz, vieram a se tornar, em um sentido mais amplo, representativos da rejeição a qualquer enfrentamento ao establishment. Os fotógrafos da peça, assim como Jim e Jaybird, são figuras com tais inclinações conservadoras, não obstante os seus esforços um tanto ridículos para escondê-las, conforme nota Leach: “Ah, mas é o fim. Eles mandam para cá dois fotógrafos quadrados"44 (Gelber, 1960, p. 38). No entanto, tais personagens não servem para uma denúncia contundente dos que se decidem pela conformação ao produtivismo capitalista e por uma rotina imersa em valores institucionalizados,

${ }^{44} \mathrm{Oh}$, this is the end. They send us two square photographers. (Tradução nossa) 
e na venalidade das medianias burguesas. Do mesmo modo, os viciados, em cujas falas o trabalho, a educação formal e a vida familiar aparecem destituídos de validade e de relevância, não compõem uma imagem engrandecida daqueles que não se adequam às demandas da sociedade estabelecida. A colocação de Cowboy de que "Existem hipsters nojentos e existem squares nojentos"45 (Gelber, 1960, p. 76) representa a tonalidade geral da obra a respeito de tal dicotomia.

Em outro recuo de um posicionamento categórico em debates frementes a partir do final dos anos 1950, o título de Gelber não tece uma análise satisfatória da segregação racial. O texto, criado durante a era Jim Crow, dita que o elenco deve ser composto por atores brancos e negros, permitindo fluidez na distribuição dos papeis, mas propondo que seja assim feita: Jim, Jaybird, Leach, Solly, Earnie e o Second Photographer seriam brancos; e Sam, Cowboy, Sister Salvation, Harry e o First Photographer seriam negros. Nos Estados Unidos, as políticas segregacionistas elaboradas após o fim da escravidão, em 1865, e em vigor até o final dos anos 1960, negavam aos negros diversos direitos civis e políticos, e os proibiam de conviver com brancos em ambientes como escolas, restaurantes, lojas, parques públicos, transportes coletivos, etc. (Dailey, Gilmore \& Simon, 2000). Embora Nova York, sede da montagem original, não tivesse tal interdição legalmente instaurada e regulada pelo governo estadual, conforme ocorria em outras regiões do país, contava, ainda assim, com a maioria dos espetáculos teatrais compostos apenas por brancos. Em tal lógica de racismo nacional faltava às plateias, afinal, a aceitação de elencos negros - infrequentes também devido às desigualdades de acesso à profissionalização artística. Nesse âmbito, na determinação de Gelber de que houvesse a presença, no palco, de quase uma mesma quantidade de negros e brancos, delineava-se uma resposta sociopolítica à questão.

Obedecendo às sugestões do autor, no espetáculo do Living Theatre, Cowboy, o fornecedor de drogas, era negro. O texto não fornece nenhum elemento a respeito de quem seria o sujeito para além de sua função de comercializador de narcóticos e o que o teria levado para o meio, e nem tampouco lhe faz falar sobre as tensões raciais que o abateriam. O único instante em que principia uma reflexão

${ }^{45}$ There are lousy hipsters and lousy squares. (Tradução nossa) 
em tal direção, quando canta a canção popular White Christmas e aponta, "Vocês sabem que vivemos em uma sociedade branca. Vocês já viram neve negra?"46 (Gelber, 1960, p.77), é interrompido. Solly lhe dá uma resposta ambígua, comentando ter visto heroína marrom no México, porém, a atenção de ambos é logo desviada para Leach, e se seguem diálogos nada relacionados à temática racial.

A bandana vermelha de Cowboy é uma eficiente ilustração da recusa de Gelber da tessitura de uma discussão mais elaborada acerca da segregação racial. Ao experimentar heroína, Jaybird - que, novamente seguindo a concepção textual, é, na produção do Living Theatre, branco - surge usando a bandana do fornecedor em seu pescoço, combinada ao terno que já vestia desde sua primeira aparição. Cowboy, por sua vez, não toma emprestado nenhum item da vestimenta do escritor. Ergue-se, aí, a sugestão da fácil visita do intelectual branco e de classe média para o lugar de um traficante de drogas, negro, para quem a mesma mobilidade inexiste. Todavia, nada mais decorre. Ao final do espetáculo, queixando-se de ter perdido o controle sobre sua criação artística, Jaybird simplesmente retira a bandana e a devolve a Cowboy, mantendo suas falas restritas ao seu processo de criação. Não à toa, "jaybird" é um substantivo comum sinonímico de "jay" (o pássaro gaio), e é também uma gíria, bastante utilizada no contexto original da peça, para se referir a alguém que fala incessantemente, sem chegar a lugar algum ${ }^{47}$.

Cowboy não representa, portanto, uma vítima marginalizada. E, enquanto traficante, não é nem uma figura vilanesca, cujo único intuito seria comercializar uma droga, sem se importar com seu perigo letal, e tampouco é um sujeito de subversividade celebrada. Seu apelido, em tal perspectiva, é propositalmente capcioso, visto que se é atestável que controla os viciados como se fossem gado, está longe de ser como um cowboy do tipo do gênero western, ágil, destemido e realizador das mais ousadas façanhas. Ele meramente surge, entrega a heroína para seus clientes - a quem compreende como "com idade suficiente para

${ }^{46}$ You know we live in a white society. Did you ever see black snow? (Tradução nossa)

47 O Merriam-Webster Dictionary indica que "jay", em uso coloquial e atualmente datado, refere-se a "an impertinent chatterer". Disponivel em <https://www.merriam-webster.com/dictionary/jay>. Acesso em: 4 mar. 2021. (Tradução nossa) 
saberem o que estão fazendo"48 (Gelber, 1960, p.74) -, e permanece fazendo-lhes companhia, em silêncio ou participando das conversas com respostas breves. Falta-lhe densidade psicológica, dramática, social e política - como falta a todas as personagens, uma vez que Gelber se furta ao exercício da caracterização complexa.

Se Jaybird diz ter obtido "a very good score" por ter adormecido antes de acabar se enovelando na conformação à tradição dramática, Gelber parece buscar um saldo positivo na diferenciação, divorciando-se tanto do mainstream quanto de posições efetivamente aliadas às manifestações de subversão de seu período. A despeito de sua composição a partir de recursos estéticos inusuais, The Connection não realiza uma teatralidade sem precedentes. Ainda assim, logra alcançar certa singularidade ao abordar a questão dos psicotrópicos, apresentar personagens hip e square, e apostar em um palco racialmente misto sem assumir a forma e o conteúdo correntes no avant-garde estadunidense contemporâneo.

Hoje, é possível defender que a maior originalidade do título de Gelber, já praticamente esquecido, é a sua recusa de uma fábula desenvolvida a partir de um conflito por meio da escolha consciente de se aferrar ao enfado, impondo-o ao público. Para Abel, a experiência do espectador diante de The Connection era simplesmente entediante: "Você se sente completamente entediado pelos viciados no palco; eles também se sentem completamente entediados, pelos outros, e por eles mesmos"49 (Abel, 1968, p.122). Enquanto os viciados se entediam na espera por Cowboy, que não tarda a ser resolvida, a plateia, por sua vez, persiste enfadada até o desfecho do espetáculo, imersa na total monotonia.

\section{O tédio como espelho}

Por seu ritmo arrastado, concentrado em personagens pouco desenvolvidas, a obra desafiava aqueles que a viam. Embora embalada por um jazz de qualidade,

\footnotetext{
${ }^{48}$ old enough to know what they're doing. (Tradução nossa)

49 You are bored stiff by the junkies on the stage; they are bored stiff too, with each other and with themselves. (Tradução nossa)
} 
ela não parecia permitir que se respondesse com facilidade à indagação do que exatamente agradaria em cada sessão. "Por que assistir a uma peça assim? [...] Acho que é a dificuldade moral para responder à questão que torna essa peça fascinante. Mas se sentir fascinado é admitir não ter um objetivo ou um propósito" 50 , alegava Abel (1968, p.126), concluindo: "Não há nada agradável em The Connection. Há um pouco de poesia e uma dose de sofrimento. Mas porque nos sentimos sacudidos, perturbados e autocontemplativos quando saímos do teatro, sabemos que vimos um bom show" ${ }^{51}$ (Abel, 1968, p.127).

Depreende-se que na poética de Gelber, mais do que as inquirições sobre as rupturas possíveis com a herança dramática tradicional, a metateatralidade, as imbricações diegéticas, ou a inserção do jazz com momentos de improvisação, sobressai o enfado. A sua linha composicional mais rica se pauta, pois, na produção consciente do tédio. Transformando-o em um espelho voltado para os espectadores, usa-o no intuito de, paradoxalmente, tanto os alhear quanto imergir na ação. O termo "the connection" é uma gíria do período sessentista para fornecedores de drogas, e, ainda, em um sentido mais geral, é uma conotação para um contato substancial a ponto de provocar algum vislumbre de transcendência. A conexão surge representada por um cowboy lacônico, letárgico e insosso, que leva as personagens para a saciação estática e momentânea com a heroína.

Diferentemente do que compreende Abel, para quem após o uso da heroína as personagens seguem entediadas, parece mais acertado ventilar que elas se encontram em um processo de prazer individual e impartilhável. Apenas para aqueles que não tomam parte e meramente testemunham o estado resulta enfastiante. Com exceção de Leach, que insiste não estar sentindo qualquer efeito, elas certamente experimentam e se abandonam a algum grau de sublimidade, que é, entretanto, intraduzível, não servindo como uma via de comunhão nem entre eles próprios, nem com as plateias.

Negando-se a ser envolvente, a peça cristaliza o imperativo de

50 Why go to see such a play? [...] I think it is the moral difficulty one feels in answering that gives this play its fascination. But to be fascinated is to admit to being without goal or purpose. (Tradução nossa)

${ }^{51}$ There is nothing delightful in The Connection. Little poetry, and a degree of pain; but from the fact that we are shaken up, disturbed and self-questioning when we leave the theatre, we know that we have seen a good show. (Tradução nossa) 
entretenimento atrelado ao teatro ou a qualquer forma de espetáculo, deixandoo, até seu desfecho, em suspensão. Em tal manobra, reflete a busca por satisfação de diferentes movimentos da rotina humana. Capturado em seu enfado, cada membro do público se reconhece como o intérprete de suas procuras individuais por contentamento - quer naquele instante, dentro da sala teatral, quer avaliando outras instâncias de seu cotidiano. Nos momentos inaugurais, um dos fotógrafos se anima com a hipótese de testemunhar um surpreendente esquema de distribuição de drogas, orquestrado por uma figura escusa, superior a Cowboy. Os viciados logo the explicam, no entanto, que tal sujeito não surgirá, e que são indiferentes ao fato de "o cara" existir ou não. "Para nós, pra onde o Cowboy vai é um mistério. Qualquer um que vem no apartamento de Leach sente que ele é o ator central de seu próprio drama. [...] O cara é você. Você é o cara. Você é a sua própria conexão"52 (Gelber, 1960, p.36-37), diz Solly, pontuando que seu interlocutor adentrara o recinto para fotografar o grupo, e estaria se envolvendo com ele por sua conta e risco.

A colocação é claramente dúbia, e não se restringe à personagem do fotógrafo: também o espectador, em certa medida, foi até o apartamento de Leach. Ao investir em um ingresso para um espetáculo que promete apresentar, na ótica mais autêntica possível, o que transcorre em um local frequentado por viciados em heroína, ele se insere, tal qual os viciados, naquela dinâmica. Logo, de saída, junta-se à espera pela chegada de Cowboy, e, a partir do segundo ato, assiste enfastiado ao contentamento dos viciados. O beco de drogas se transforma, pois, em um microcosmo representativo da busca por prazeres. Compreendida em termos mais amplos, a conexão figura, aqui, como uma ação principiada e experimentada individualmente. Incomunicável, agrada e gera sentido somente para aqueles que têm os mesmos prazeres - sejam eles psicotrópicos, a religião praticada por Sister Salvation, uma sessão teatral, trabalho, dinheiro, moda, zelo com a saúde, etc.

Em seu caráter pontual e fugaz, o objeto prazeroso fatalmente induziria ao vício, mais ou menos aceitável conforme a sua legalidade em uma determinada

52 To us it is a mystery where Cowboy goes. Anyone coming to Leach feels that he is the central actor in his own drama. [...] The man is you. You are the man. You are your own connection. (Tradução nossa) 
sociedade. Como Sam e Solly propõem:

SAM: [...] As pessoas que andam nas ruas, as pessoas que trabalham todos os dias, as pessoas que se preocupam tanto com o próximo dólar, o próximo casaco, os dependentes de clorofila, os dependentes de aspirina, os dependentes de vitaminas, essas pessoas são mais viciadas do que eu. Mais do que eu. Viciadas. [...]

SOLLY: Elas são. Cara, claro que elas são. Você só tem um vício que é ilegal"53 ( Gelber, 1960, p.31).

A placa que adorna uma das paredes do cenário, segundo descrevem as rubricas, na qual se lê "Paraíso ou Inferno: em qual via você está?"54 (Gelber, 1960, p. 17) assinala a proximidade entre as personagens e os espectadores. Os sujeitos no apartamento de Leach seguram um espelho para o público, tentado a não se pensar em nada semelhante a viciados em heroína, mas ali mergulhado, aguardando por mais uma dose de entretenimento e satisfação, tal como um usuário de narcóticos espera por prazer em uma droga. Em tal ótica, a quase overdose mortal de Leach, que insiste não estar sentindo os efeitos da substância, não deve servir como um episódio alarmista e nem mesmo consolador para o membro da plateia, inclinado a reconhecer ali o inferno, enquanto as suas distrações, não-letais, seriam o paraíso. A conexão, qualquer que seja ela, é necessariamente efêmera, e, por isso, voltará a ser buscada, viciando.

Ao final, tem-se a impressão de que os eventos transcorridos integram uma noite indistinta para Cowboy, Leach, Solly, Sam e Earnie, e ocorrem com frequência. Também o espectador, terminada a sessão, buscará as suas várias outras fontes diárias de contentamento: um jantar após o espetáculo, novas peças, a leitura de um romance, bebidas alcóolicas, cigarros, compras, o consumo de pornografia, idas a bares, etc. Ainda que seja fácil reconhecer o vício em heroína como autodestrutivo e, consequentemente, julgá-lo repulsivo, haveria mesmo tanta diferença entre ele e os vícios legais? Contentamentos mortíferos seriam decadentes, e uma vida inteira dedicada a deleites amenos seria engrandecedora?

\footnotetext{
${ }^{53}$ SAM: [...] The people who walk the streets, the people who work every day, the people who worry so much about the next dollar, the next coat, the chlorophyll addicts, the aspirin addicts, the vitamin addicts, those people are hooked worse than me. Worse than me. Hooked. [...]

SOLLY: They are. Man, sure they are. You happen to have a vice that is illegal. (Tradução nossa)

${ }^{54}$ Heaven or Hell: which road are you on? (Tradução nossa)
} 
De acordo com Howard Hewes, The Connection

deliberadamente evita os clichês estruturais que a fariam se adequar às especificações do que consideramos 'uma peça'. Isto é, não possui um herói, não nos manda para casa com uma mensagem, e não indica qualquer resolução para os problemas que as suas personagens atormentadas enfrentam ${ }^{55}$ (Hewes, 1960, p.39).

Privado de uma conclusão para as situações das personagens, o espectador sai levando consigo apenas o retrato de buscas por satisfação, e a cristalização de sua própria espera, ali, pela cessação do tédio. O espetáculo deliberadamente não se faz entretecedor - e, se o espectador o aprova, não é tanto, como ventilava Abel, pelo cinismo de quem sabe estar sem um objetivo ou um propósito, mas justamente porque termina por abraçar a encruzilhada na qual Gelber o deposita. Isto é, na qualidade de público, vai ao teatro com o intuito de se contentar, sabendo que a finalidade costumeira da arte teatral é fornecer algum tipo de entretenimento. Todavia, é surpreendido pela desembaraçada recusa de The Connection em se adequar à tal padrão. Tal como os frequentadores do apartamento de Leach na diegese, ele, um visitante por uma breve sessão, tornase o protagonista de sua própria peça, uma espera infrutífera. São as diversas reflexões das muitas e incessantes buscas individuais por prazer, portanto, que agradam - porque, segundo Gelber, não se age fora disso, somos todos viciados, enfim. Nesse sentido, ao contrário do que afirma Hewes, estaria aí uma mensagem, ainda que de contornos um tanto vagos.

Nas temporadas seguintes ao êxito da produção de 1959 poucas novas montagens do título foram realizadas nos Estados Unidos ou em outros países. Em 2009, passadas cinco décadas do estrondo inicial, o Living Theatre realizou um revival comemorativo do título, que se mostrou relevante essencialmente em termos nostálgicos e memorialistas. Para Alexis Soloski (2009, p.2):

As experimentações formais de Gelber - mecanismos de enquadramento, suposto uso da improvisação, a dissolução da quarta parede, ausência de enredo - não eram novas em 1959 (ele as toma

55 [...] deliberately avoids the structural clichés which would make it fit the specifications of what we have to think of as a "play". That is, it has no hero, it doesn't send us home with a message, and it indicates no resolution of the problems that face its troubled characters. (Tradução nossa) 
emprestadas de Odets, Beckett, Pirandello e Shakespeare). E são ainda mais antigas hoje. ${ }^{56}$

Por dois anos The Connection provocou o seu público, mesclando metateatralidade, heroína e jazz, e fazendo um uso singular do enfado. Possivelmente fenômeno cultural algum na história teatral recente dos Estados Unidos se recusou tão desavergonhadamente a entreter - e, ainda assim, agradou.

\section{Referências}

ABEL, Lionel. Not Everyone is in the Fix. In: ABEL, Lionel. Metatheatre: A New View of the Dramatic Form. New York: Hill \& Wang, 1968.

ATKINSON, Brooks. The Connection: Jack Gelber's Harrowing Drama About Social Life Amongst the Junkies. New York Times, New York, February 07, 1960. Section 2, Part 1, p. X.

BOTTOMS, Stephen J. Playing Underground: A Critical History of the 1960s Off-OffBroadway Movement. Ann Arbor: University of Michigan Press, 2009.

DAILEY, Jane; GILMORE, Glenda Elizabeth \& SIMON, Brian (Edited by). Jumpin' Jim Crow: Southern Politics from Civil War to Civil Rights. Princeton and Oxford: Princeton University Press, 2000.

BRUSTEIN, Robert. Seasons of Discontent: Dramatic Opinions - 1959 - 1965. New York: Simon and Schuster, 1967.

CALTA, Louis. The Connection: A Play About Junkies. New York Times, New York, July 16, 1959. P. 30.

CARLSON, Marvin. Ten Thousand Nights: Highlights from 50 Years of Theatre-Going. Ann Arbor: University of Michigan Press, 2017 (Kindle Edition).

GELBER, Jack. The Connection. New York: Grove Press, 1960.

GITLIN, Irving (Producer). "The Nation's Nightmare" - Narcotics/ Waterfront - A Report Of Crime In America in 1951. New York: CBS Radio, 1952.

HEWES, Howard. Off-Broadway. In: KROENENBERGER, Louis (Edited by). The Best Plays of 1959 - 1960. New York: Dodd, Mead and Company, 1960.

${ }^{56}$ Gelber's formal experiments_framing devices, apparent use of improvisation, the dissolving of the fourth wall, plotlessness-weren't new in 1959 (he borrows from Odets, Beckett, Pirandello, and Shakespeare). And they're older now. (Tradução nossa) 
HORNBY, Richard. Drama, Metadrama, and Perception. Lewisburg: Bucknell University Press, 1986.

LUTZ, H. B. Some Words on "The Connection". The Village Voice, New York, August 05, 1959. P. 09.

Merriam-Webster English Dictionary. Disponível em: < https://www.merriamwebster.com/>. Acesso em: 04. mar. 2021.

PAVIS, Patrice. Dicionário de teatro. Tradução sob a direção de J. Guinsburg e Maria Lúcia Pereira. São Paulo: Perspectiva, 2017.

SELL, Mike. Avant-Garde Performance and the Limits of Criticism. Ann Arbor: The University of Michigan Press, 2011.

SOLOSKI, Alexis. Pricks and Kicks in The Connection and The Judgement of Paris. The Village Voice, New York, January 21, 2009. Disponível em: <https://www.villagevoice.com/2009/01/21/pricks-and-kicks-in-the-connectionand-the-judgement-of-paris/>. Acesso em: 04 mar. 2021.

SOVA, David B. Banned Plays: Censorship History of 125 Stage Dramas. New York: Facts on File, Inc., 2004.

TALLMER, Jerry. Theatre: The Connection. The Village Voice, New York, July 22, 1959, p. 09.

TYNAN, Kenneth. Preface. In: GELBER, Jack. The Connection. New York: Grove Press, 1960.

Recebido em: 12/03/2021

Aprovado em: 03/06/2021 